\title{
O MAPEAMENTO DE BIÓTOPOS COMO FERRAMENTA PARA IDENTIFICAÇÃO DE CONFLITOS AMBIENTAIS: UM ESTUDO DE CASO NA CIDADE DE SANTA MARIA-RS
}

\author{
Roberto Luiz dos Santos Antunes'; Adriano Severo Figueiró ${ }^{2}$ \\ (recebido em 18.06.2010 e aceito para publicação em 08.07.2011)
}

\section{RESUMO}

O estudo dos biótopos tem se revelado uma ferramenta valiosa para o entendimento da complexidade dos sistemas ambientais em áreas urbanas, permitindo uma melhor compreensão das potencialidades e necessidades que se colocam na relação uso/ preservação. Neste contexto, teve-se como objetivo a realização do mapeamento dos biótopos urbanos presentes no bairro Nossa Senhora do Perpétuo Socorro em Santa Maria, RS, classificando o tipo de biótopo e sua estrutura. A metodologia aplicada foi adaptada e aperfeiçoada à realidade local a partir de trabalhos desenvolvidos na Alemanha e no Brasil, caracterizando-se pela análise em nível de detalhe das unidades de paisagem, que proporcionam um amplo conhecimento acerca da funcionalidade ambiental, dos níveis de ocupação do solo, e da vegetação existente. Cada biótopo foi classificado dentro de uma classe que expressa o grau de impermeabilização do solo, além do levantamento da estrutura da área livre. A vegetação arbórea, arbustiva e herbácea foi identificada em $91,20 \%$, já o restante dos biótopos, não possui nenhum tipo de vegetação expressiva, havendo somente áreas construídas e pequenos jardins.

Palavras-chave: Vegetação urbana; Planejamento ambiental; Geoecologia urbana.

\footnotetext{
${ }^{1}$ Geógrafo, Mestrando em Geografia, POSGEA, UFRGS, Porto Alegre, RS - roberto.anthunes@gmail.com

${ }^{2}$ Prof. Dr., Departamento de Geografia, UFSM, Santa Maria, RS - adri.geo.ufsm@gmail.com
} 


\title{
THE MAPPING OF BIOTOPES AS TOOL FOR IDENTIFICATION OF ENVIRONMENTAL CONFLICTS: A CASE STUDY IN SANTA MARIA CITY, RS
}

\begin{abstract}
The study of biotopes has been considered an important tool to understanding the complexity of environment systems in urban areas, allowing a better evaluation of potentialities and necessities presented in the relation use/preservation. Considering this fact, the objective of this work is to map urban biotopes in Nossa Senhora do Perpétuo Socorro neighborhood in Santa Maria, RS, by classifying the kind of biotope and its structure. The applied methodology was adapted and improved to local reality from works developed in Germany and Brazil, it is characterized by detailed analysis of landscape units, thus it provides a great knowledge about environmental functionality, levels of soil occupation and existing vegetation. Each biotope was classified in a class that expresses the level of soil impermeability and the structural survey of free area. Trees, shrubs and herbaceous vegetations were identified in $91.20 \%$. The rest of biotopes do not have any kind of expressive vegetation presenting only constructed areas and small gardens.
\end{abstract}

Keywords: Urban vegetation; Environmental planning; Urban geoecology.

\section{INTRODUÇÃO}

Nas últimas décadas a urbanização nas cidades se expandiu consideravelmente, sobretudo nas regiões metropolitanas e nas cidades de porte médio. Este processo tem originado graves conseqüências para a qualidade ambiental e para o bem-estar da população.

Uma demonstração disto é o crescimento da população urbana no nosso país, que de acordo com o Instituto Brasileiro de Geografia e Estatística (2000), na década de 70 era de $30,5 \%$, chegando ao ano 2000 a $81 \%$ de população vivendo em cidades. Este crescimento não vem acompanhado de grandes planos urbanísticos para assentar toda esta demanda a mais de população nas nossas cidades, fazendo com que ocorra um 
desequilíbrio ambiental generalizado nas grandes cidades, prejudicando de várias formas o meio ambiente urbano. Segundo Mello (1995, p.23),

\begin{abstract}
Os problemas ambientais que vivenciamos atualmente não são novos, mas sim um agravamento de um conjunto de problemas antigos, pois o surgimento e consolidação das sociedades, desde os tempos mais remotos, sempre se deu à custa de transformações e explorações do espaço e dos recursos naturais disponíveis na natureza, ocasionando impactos ambientais.
\end{abstract}

Problemas antes imperceptíveis agora começam a surgir, fazendo com que as pessoas comecem a ter outra visão diante da perspectiva ambiental. A diminuição dos espaços livres, o caos no trânsito e a artificialização dos espaços livres, tem se tornado, cada vez mais, obstáculos à saúde das pessoas.

Somando-se a isso, as conseqüências da urbanização resultam na formação de ilhas de calor, que aumenta a temperatura e a sensação térmica. Outra importante conseqüência são as enchentes, provocadas, sobretudo pelas estruturas impermeáveis utilizadas, como a pavimentação asfáltica das ruas, o concreto das calçadas e das áreas livres de prédios e casas.

Além disto, a artificialização do complexo urbano, associado com a presença reduzida das áreas verdes, diminui consideravelmente o número de espécies da fauna, que se utilizam da vegetação como habitat. Neste caso, devido à redução da vegetação as espécies existentes não conseguem expandir horizontalmente por não terem corredores biológicos que possuem a função de conservação e aumento da biodiversidade.

A implementação de áreas verdes em ambientes urbanos é uma fonte de atenuação de diversas formas de desequilíbrios ambientais decorrentes da perda da funcionalidade climática e hidrológica das cidades. Assim, Spirn (1995) afirma que o cultivo do bioma urbano requer uma mudança nos enfoques correntes de seleção e projeto dos espaços livres urbanos e no plantio e manutenção da vegetação urbana.

Segundo Baker et al. (2003), uma das soluções para amenizar os problemas causados pela excessiva impermeabilização do solo por materiais que elevam a amplitude térmica das cidades é tratar o meio urbano com vegetação, especialmente seu componente arbóreo.

Nucci (2008, p.24) afirma também que "[...] dentro da linha metodológica do planejamento da paisagem, quando se fala em planejar com a natureza, está se falando principalmente da vegetação. É a partir dela que muitos problemas são amenizados ou resolvidos".

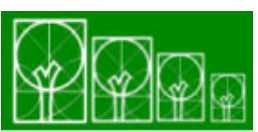

$\mathbf{S} \cdot \mathbf{B} \cdot \mathbf{A} \cdot \mathbf{U}$ Soc. Bras. de Arborização Urbana 
Todavia, a necessidade de uma concepção mais dinâmica e complexa da natureza em substituição aos modelos rígidos e estruturados, representa atualmente um dos maiores desafios aos estudos de paisagens urbanas. Assim, uma das categorias fundamentais a ser compreendida na paisagem é justamente sua estrutura, uma vez que segundo Saito (1998) os processos aparentam clara subordinação aos elementos ou, em outras palavras, as funções apresentam-se subordinadas à estrutura.

Nesse contexto, Sirkis (1999) afirma que o mínimo aceitável num bairro são quinze metros quadrados de área verde por habitante, incluindo-se nesta área verde não só as copas das árvores como outros tipos de vegetação. Entretanto, essa vegetação não deve estar isolada, pois para um ambiente urbano saudável, não basta criar espaços verdes, jardins, praças ajardinadas, ou mesmo parques, sem entender como eles se integram e se relacionam com as ruas vizinhas, seu entorno, seu bairro.

Nesse caso, é necessário classificar os bairros levando-se em conta a relação verde versus área construída para trabalhar especificamente sobre os locais de perfil critico que estão também entre os socialmente mais carentes (Sirkis, 1999).

É este o contexto em que se inclui o estudo dos biótopos ${ }^{3}$, que tem se revelado uma ferramenta valiosa para o entendimento da complexidade dos sistemas ambientais em áreas urbanas, permitindo uma melhor compreensão das potencialidades e necessidades que se colocam na relação uso/ preservação.

Os biótopos são, assim, a expressão das relações que determinam o nível de equilíbrio entre os elementos bióticos e abióticos da paisagem, a partir da mediação da interferência antrópica. Para Troppmair (1984, p.59):

Com o desaparecimento de espaços naturais, ou seja, aqueles não afetados pelo homem, o termo biótopo passa a ter simultaneamente o sentido de 'área que merece ser protegida, pois são espaços bio-ecológicos importantes', [...]. O mapeamento e o estudo de biótopos não têm por finalidade somente registrar sua ocorrência, mas, numa visão mais ampla, significa preservar, manejar corretamente e mesmo preservar estas áreas.

Cada biótopo assume uma função ambiental específica no conjunto da paisagem. Em função disso, o tratamento ou manejo isolado de uma determinada porção do território

\footnotetext{
${ }^{3}$ Os biótopos (área ocupada por uma biocenose) representam unidades de paisagem, de tamanho variável, cujos elementos (físicos, bióticos e antrópicos) mantêm características homogêneas na sua estrutura fisionômica, o que permite identificá-los e diferenciá-los em um estudo da paisagem. A metodologia de mapeamento de biótopos consiste justamente no reconhecimento e delimitação de parcelas da paisagem com base na sua identidade ecológica.
}

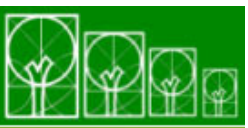

$\mathbf{S} \cdot \mathbf{B} \cdot \mathbf{A} \cdot \mathbf{U}$ Soc. Bras. de Arborização Urbana 
mostra-se, por vezes, inócuo já a médio prazo, uma vez que esta porção é parte integrante (e influente) da qualidade de um espaço maior.

A aplicação nas áreas urbanas dos conhecimentos acumulados na Geoecologia, especialmente no que se refere à biogeografia de ilhas ${ }^{4}$, representa hoje um elemento decisivo no processo de conservação da biodiversidade. Turner (apud SAITO, 1998, p. 16) afirma:

Como a sobrevivência das populações numa paisagem depende da taxa de extinção local (no fragmento) e também da taxa de deslocamento individual entre fragmentos, espécies em fragmentos isolados devem ter probabilidade menor de persistência.

Os corredores e os fragmentos florestais urbanos ${ }^{5}$, além da importante função já assinalada de contribuir para a preservação da biodiversidade, também desempenham funções estratégicas no interior das cidades. Dentre estas funções, pode-se citar a preservação de mananciais, a captação do escoamento superficial, a redução dos níveis de ruído e de poeiras em suspensão, além de proporcionar condições de lazer à população em geral.

A cidade de Santa Maria e, por conseqüência o Bairro Nossa Senhora do Perpétuo Socorro, não representa uma exceção a este modelo "biocida" de urbanização das cidades médias brasileiras, pois o processo histórico de ocupação de seu território responde pela retirada e/ou fragmentação de uma formação florestal que originalmente se estendia a partir do rebordo do planalto, penetrando pela várzea dos rios que ali tem a sua origem (LUCAS; ANTUNES; FIGUEIRÓ, 2008).

Cabe lembrar que, ao ocupar o sopé da montanha a partir de uma densificação urbana que desconsiderou a existência de parques ou áreas verdes, a cidade de Santa Maria condenou os fragmentos florestais à jusante da área urbana, a um processo de isolamento (fig.1) que, invariavelmente, tem levado a uma redução expressiva da biodiversidade local (FIGUEIRÓ, 1997).

\footnotetext{
${ }^{4}$ Carbonari (1981) chama a atenção para a necessidade de se pensar o conceito de "ilha" no seu sentido mais amplo, extrapolando a definição geográfica a que o termo muitas vezes permanece restrita.

${ }^{5}$ Utiliza-se, neste caso, o conceito referido por Forman e Godron (1986), no qual os "corredores" representam os elementos de conexão entre os fragmentos isolados que, ao facilitar ou inibir a movimentação de indivíduos, contribui para a manutenção da biodiversidade, através do aumento da imigração e da redução do grau de isolamento populacional.
} 
Inserido neste contexto, o diagnóstico ambiental do bairro Nossa Senhora do Perpétuo Socorro (Santa Maria - RS) propõe uma análise detalhada das unidades de paisagem, caracterizando o grau de impermeabilização do solo, quantificando as áreas verdes e indicando os locais que estão com sua estrutura paisagística mais degradada.

Esse estudo introduz a metodologia de mapeamento de biótopos, que se caracteriza pela análise em nível de detalhe das unidades de paisagem, proporcionando um amplo conhecimento acerca da funcionalidade ambiental e dos níveis de ocupação do solo, verificando também a situação da vegetação existente.

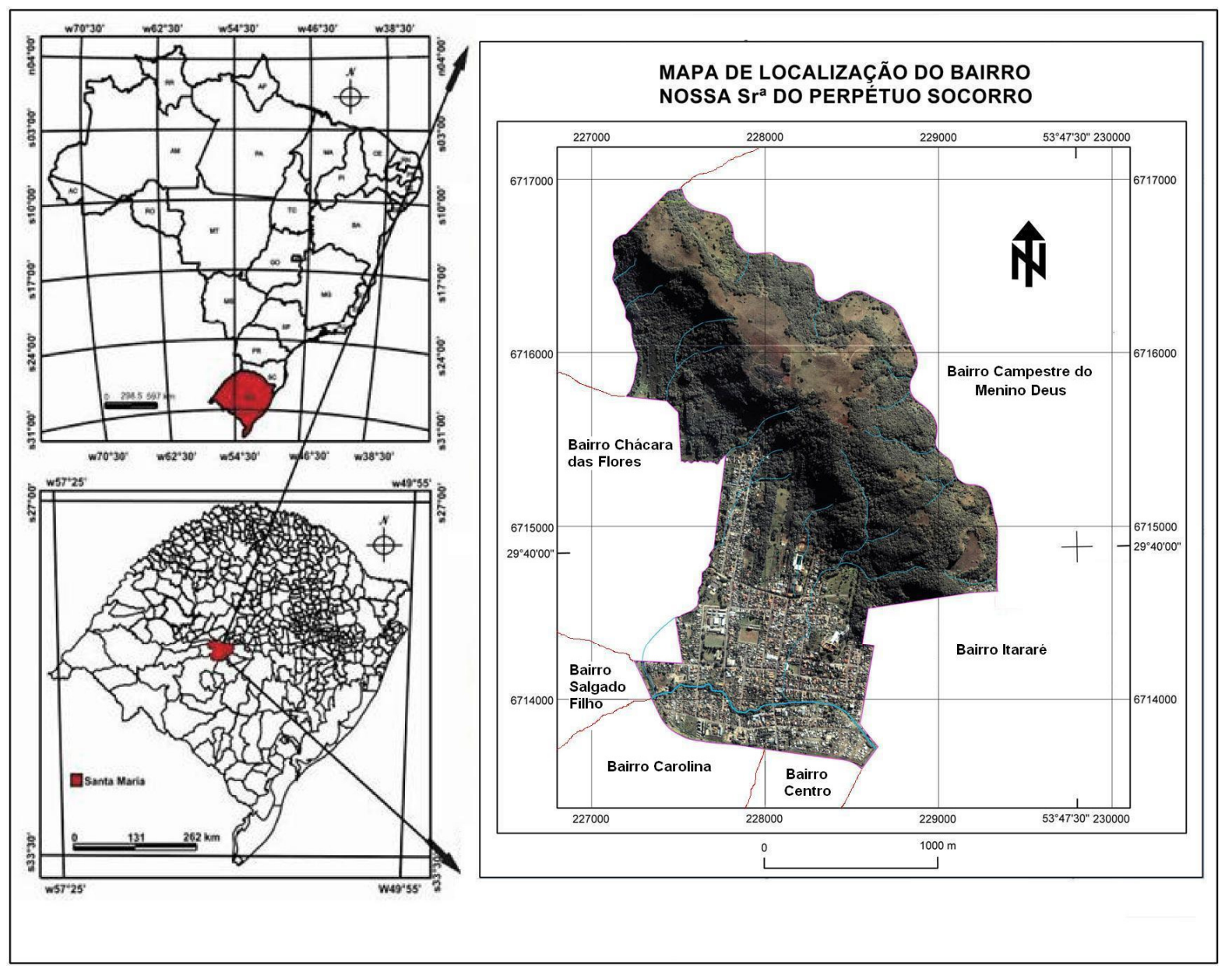

Fonte: Lucas, Antunes e Figueiró (2008)

FIGURA 1: Localização do Bairro Nossa Senhora do Perpétuo Socorro.

FIGURE 1: Location of Nossa Senhora do Perpétuo Socorro neighborhood.

A cidade de Santa Maria localiza-se na região central do Estado do Rio Grande do Sul, entre as coordenadas de $29^{\circ} 39^{\prime}$ e $29^{\circ} 43^{\prime}$ de latitude sul e entre $53^{\circ} 50^{\prime}$ e $53^{\circ} 45^{\prime}$ de 
longitude oeste.

Geomorfologicamente a cidade ocupa uma planície sedimentar nos contrafortes do Planalto Meridional brasileiro, apresentando no seu quadro biogeográfico uma nítida transição entre a Floresta estacional decidual e os campos sulinos.

A maior parte da cidade encontra-se assentada sobre a formação geológica Santa Maria, de origem sedimentar, sendo que o relevo resultante caracteriza-se por coxilhas suaves, com declividades inferiores a 6\%, com altitudes que não ultrapassam os 150 metros (SARTORI, 2000).

A ocupação humana ao longo da história em uma área fisicamente tão diversificada, também apresentou formas, ritmos e tempos bastante diferentes, permitindo que se descortine um jogo de relações tão próprio desta região e, ao mesmo tempo, inserido em todo um contexto de transformação pelo qual passaram as demais áreas da antiga Província de São Pedro.

É possível considerar que a devastação florestal na atual cidade de Santa Maria teve início, segundo Rambo (1994), com o estabelecimento das primeiras estâncias de criação de gado que retiravam da mata galeria as madeiras nobres imigrantes da Floresta Decidual, como o cedro (Cedrela fissilis), o louro (Cordia trichotoma), a timbauva (Enterolobiun contortisiliquum) e a guajuvira (Patagonula americana), para a construção de cercas, casas e galpões.

Mais tarde, com o estabelecimento, em 1887, da Quarta colônia italiana em Silveira Martins, parcialmente incorporada ao município de Santa Maria a partir de 1888 (BELÉM, 1989), a área florestal do rebordo do planalto passa a ser mais fortemente atingida.

A retirada desta mata constituiu a primeira grande transformação na paisagem do rebordo do planalto (fig.2). Fosse para a liberação de áreas para o plantio, fosse para servir à nascente indústria moveleira, a derrubada da floresta era imprescindível à sustentação daquele modo de vida dotado de poucos recursos.

A isso se associou a necessidade de extração de lenha para alimentar as locomotivas que começavam a circular em Santa Maria. Tal necessidade levou a um desmatamento não só da mata de encosta, como também das matas-galeria que margeavam os cursos dos rios, o que levou progressivamente ao desaparecimento absoluto de muitos trechos desta última.

Paralelamente à fragmentação da área florestal original, jamais houve a preocupação do poder público municipal em estabelecer qualquer tipo de política conservacionista para a cidade de Santa Maria. A ausência de espaços públicos com paisagens preservadas, e o

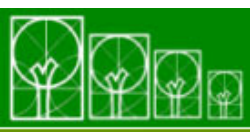

S $\cdot \mathbf{B} \cdot \mathbf{A} \cdot \mathbf{U}$ Soc. Bras. de Arborização Urbana 
avanço da propriedade privada contribuíram para a fragmentação ainda maior das áreas florestais em Santa Maria, com um progressivo aumento da superfície de impermeabilização (ROCHA; FIGUEIRÓ, 2006).

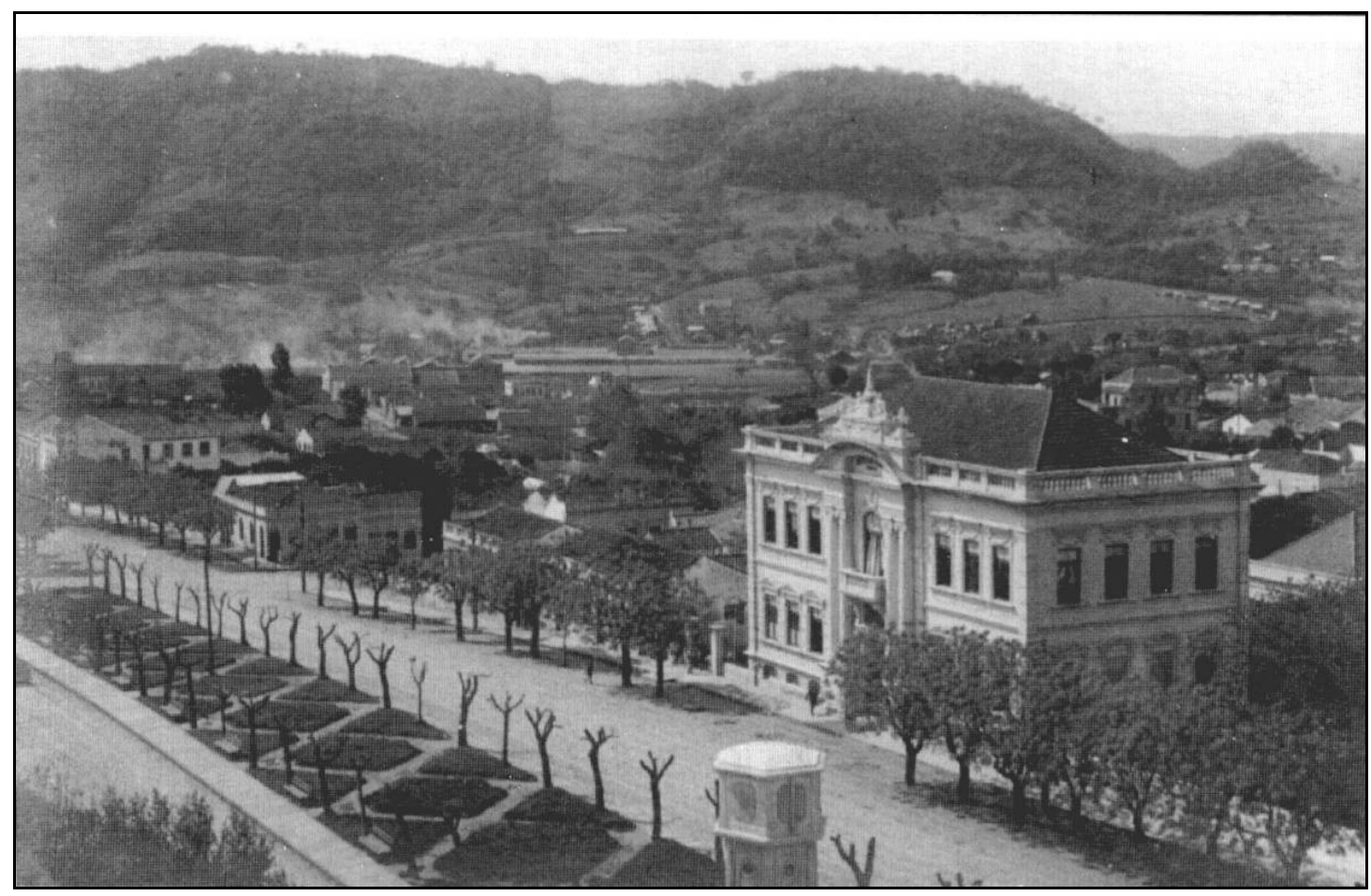

Fonte: Marchiori e Noal (1997)

FIGURA 2 - Cena da cidade de Santa Maria ao início do século, tendo no primeiro plano uma das principais avenidas da cidade e ao fundo, nas nascentes do arroio Cadena, a escarpa arenito-basáltica com a floresta estacional sub-caducifólia já bastante impactada.

FIGURE 2 - View of Santa Maria city in the beginning of century, showing in foreground one of the most important city avenues and in background, the headwaters of Cadena stream, the basaltic-sandstone scarp, with sub-deciduous seasonal forest already very impacted.

O relato de João Borges Fortes, ao cruzar pela cidade em 1904, já evidenciava de pronto esta questão:

As principais ruas da cidade de Santa Maria são ruas calçadas, regularmente edificadas e bem cuidadas. Todavia as praças não são como seria para desejar. Ressentem-se da falta de arborização e ajardinamento, o que seria para a população um refrigério na estação calmosa, além de constituir-se num ponto de convergência e distrações (MARCHIORI; NOAL, 1997, p.86). 


\section{MATERIAIS E MÉTODOS}

O conhecimento em nível de detalhe da estrutura e da organização do espaço das áreas urbanas, com a identificação dos locais que sofreram impactos, devido á ação antrópica e, paralelamente, a delimitação das áreas que apresentam indícios de contribuir com o aumento da qualidade ambiental, são imprescindíveis nos trabalhos que possuem como temática o planejamento ambiental das cidades.

Neste sentido, o desenvolvimento de metodologias eficientes deve se configurar em elemento essencial para que este objetivo seja atendido. Desta forma, o mapeamento das unidades de paisagem e a caracterização destas áreas urbanas aparecem como elemento de fundamental importância para a análise conjunta destas estruturas e sua conseqüente funcionalidade ambiental.

É importante ressaltar que a escolha do bairro Nossa Senhora do Perpétuo Socorro como área de estudo deve-se, principalmente, à existência de grandes áreas vegetadas, também, com a característica residencial do mesmo. Desta forma, seria possível fazer a comparação do bairro com outras áreas da cidade de Santa Maria que já haviam sido objetos de pesquisa com o uso da mesma metodologia, áreas estas que possuem características totalmente análogas ás atribuídas ao bairro Perpétuo Socorro.

Seguindo-se estas considerações, a primeira etapa desta pesquisa consistiu na elaboração da chave de biótopos, utilizada para a classificação dos biótopos identificados no bairro Nossa Senhora do Perpétuo Socorro (quadro 1). Esta metodologia ${ }^{6}$ vem sendo aperfeiçoada constantemente através da realização de trabalhos que avaliaram a qualidade ambiental do espaço urbano de Santa Maria (LUCAS; ANTUNES; FIGUEIRÓ, 2008), portanto, adaptando-se às realidades locais. Para o trabalho de campo, foi elaborado um mosaico de Imagens de satélite multiespectral IKONOS II que serviram de apoio para a identificação da estrutura das unidades de paisagem. Juntamente com esta etapa foi realizada a delimitação do bairro Perpétuo Socorro, utilizando-se o mapa da divisão administrativa urbana de Santa Maria-RS, do ano de 2006, na escala de 1:15.000.

Em campo, foi realizado o cadastramento dos biótopos, procedendo-se a identificação e delimitação dos mesmos de acordo com a chave de biótopos apresentada no quadro 1. Para esta operação foi utilizada uma planilha de registro dos biótopos. Esta planilha continha informações como a estrutura da área livre de cada biótopo, identificando a

\footnotetext{
${ }^{6}$ A adaptação da metodologia de mapeamento de biótopos foi feita a partir da metodologia desenvolvida na Alemanha, a partir dos trabalhos de Schulte et al (1993) e introduzida no Brasil por Bedê et al (1997).
} 
presença de árvore, arbusto, gramínea, jardim, calçada, solo exposto, horta, brita e calçamento, e os que não possuem área livre.

Cada biótopo foi classificado dentro de uma classe que expressa o grau de impermeabilização do solo, na seguinte ordem: de 0 a 30\% (baixo); de 30 a 60\% (médio); ou de 60 a 100\% (alto) de impermeabilização. Cabe destacar que os percentuais de impermeabilização atribuídos para cada unidade de paisagem foram definidos a partir da visualização de cada lote, não sendo feita nenhum tipo de cálculo matemático. Entretanto, é possível afirmar que a margem de erro nesta operação é muito reduzida, pois, as classes de impermeabilização possuem um intervalo percentual que generaliza as unidades dentro dessas classes.

Para a eficiência do mapeamento utilizou-se como nível de análise o lote individual, ou seja, a delimitação da unidade de paisagem coincidiu em quase todos os casos, com o terreno das residências. Este fato colaborou com a identificação, pois, as alterações e modificações que ocorrem na estrutura dos biótopos, são mais visíveis em cada lote, e afetam todo o conjunto do bairro.

\section{CHAVE DE BIÓTOPOS}

1 - Prédios antigos/históricos;

11 - Ruas e avenidas:

2 - Prédio;

3 - Conjunto de prédios;

4 - Residências;

5 - Prédios de uso público;

6 - Estabelecimentos comerciais;

7 - Praças e parques:

7.1 - Manejados;

7.2 - Não manejados;

8 - Áreas de lazer:

8.1 - Com alta impermeabilidade;

8.2 - Com baixa impermeabilidade;

9 - Curso d'água;

9.1 Lagos/açudes/barragens (massa d'água);

9.2 - Córregos/rios/riachos (linha d'água);

10 - Instalações ferroviárias;

11.1 - Com canteiro central;

11.1.1 - Asfaltada;

11.1.2 - Calçada;

11.1.3 - Sem pavimentação;

11.2 - Sem canteiro com vegetação;

11.2.1 - Asfaltada;

11.2.2 - Calçada;

11.2.3 - Sem pavimentação;

11.3 - Sem canteiro sem vegetação;

11.3.1 - Asfaltada;

11.3.2 - Calçada;

11.3.3 - Sem pavimentação;

12 - Estacionamentos:

13 - Áreas livres:

13.1 - Florestais;

13.2 - Capoeira;

13.3 - Gramíneas;

13.4 - Solo exposto;

13.5 - Impermeabilizadas;

14 - Área militar;

15 - Estabelecimentos industriais;

16 - Área de uso agrícola;

FIGURA 3 - Chave de biótopos utilizada para a interpretação das unidades de paisagem presentes no bairro em estudo.

FIGURE 3 - Biotopes key used for interpreting the landscape units present in studied neighborhood. 
Desta forma, optou-se pela coleta de dados através da utilização das imagens de satélite no levantamento em campo para atualizar possíveis alterações. É preciso ressalvar que se considerou apenas o que podia ser visualizado pela calçada, uma vez que, embora a pretensão fosse de investigar o interior de cada lote, para fazer o levantamento de seu uso total, na maioria dos casos o acesso aos fundos dos terrenos demonstrou-se em determinadas situações impenetrável.

Após as etapas realizadas em campo iniciou-se o trabalho de laboratório, com o georreferenciamento da imagem de satélite, a digitalização dos biótopos identificados em campo e a montagem do banco de dados. A delimitação dos biótopos procedeu-se com o desenho do perímetro respectivo de cada biótopo verificado em campo, e a montagem do banco de dados foi realizada com a utilização do software ArcGIS 9.1. Cabe ressaltar que para a quantificação dos dados, utilizou-se o programa Microsoft Excel 2003.

O primeiro mapa confeccionado foi o do Espaço Livre Arborizado (ELA), que consiste na identificação e quantificação das áreas com vegetação arbórea e arbustiva do bairro Nossa Senhora do Perpétuo Socorro. Este mapa foi elaborado seguindo-se a metodologia, proposta por Silva Filho et al. (2005), que se define como o somatório de toda a área das copas das árvores e arbustos detectadas na imagem de satélite, compreendendo o que existe atualmente de cobertura no bairro imageado. Este mapa foi obtido por meio de interpretação visual da imagem de satélite multiespectral IKONOS II do ano de 2008, com checagem a campo para a identificação de locais que ficaram sobrepostos a outras estruturas ou até mesmo pela sombra das residências, impossibilitando sua visualização através da imagem.

Além disto, foram cruzados para a finalização deste mapa os biótopos que possuem ou não qualquer tipo de vegetação (árvores, arbustos e gramíneas). Desta forma, obteve-se um mapa na escala 1:15.000.

Posteriormente foi confeccionado o mapa da impermeabilização da área de estudo (escala de 1:15000) considerando as classes de impermeabilização propostas na metodologia: de 0 a 30\% (baixo); de 30 a 60\% (médio); ou de 60 a 100\% (alto) de impermeabilização.

Outro mapa confeccionado foi o do total de unidades de paisagem identificadas no bairro. Neste, foi possível a visualização completa de toda a área de estudo, sendo possível 
também a visualização de ruas, da rede de drenagem e dos bairros que fazem limite com a área de estudo, numa escala de 1:1500.

A partir da pesquisa "Ocupação Irregular em Áreas de Preservação Permanente no Bairro Nossa Senhora do Perpétuo Socorro, Santa Maria/RS: Legislação e Conflitos" foi realizado o cruzamento dos dados das residências que estão sobrepostas às áreas de preservação permanente, identificando os percentuais de vegetação presentes e os índices de impermeabilização das unidades de paisagem.

Para a ilustração da situação que se encontra o Arroio Cadena, foi confeccionado um mapa (escala 1:6000) com o recorte do referido arroio, mostrando as áreas que possuem vegetação arbórea e arbustiva, associados com as unidades de paisagem que possuem ou não qualquer tipo de vegetação em suas áreas livres.

A última etapa da pesquisa consistiu na análise conjunta de todos os dados com os mapas confeccionados para a análise, geração dos resultados e outras considerações sobre a situação ambiental do bairro Nossa Senhora do Perpétuo Socorro.

Torna-se fundamental para o entendimento desta pesquisa a conceituação dos termos utilizados para a caracterização e mapeamento da área de estudo, desta forma, abaixo são elencados alguns conceitos:

- Área livre: é o espaço livre de construção, localizado dentro do lote de cada residência ou fixado no entorno de praças, parques e ao longo de ruas e avenidas, por exemplo. De acordo com Nucci (2006, p.50) "Os espaços livres podem ser privados, potencialmente coletivos ou públicos e podem desempenhar, principalmente, funções estética, de lazer e ecológico-ambiental, entre outras".

- Funcionalidade ambiental: refere-se aos serviços ambientais desempenhados pelo sistema natural, no caso do solo permeável, a funcionalidade está ligada aos processos de recarga do lençol freático, através da infiltração da água da chuva e ao armazenamento e redistribuição da mesma. Já para a vegetação a funcionalidade relaciona-se a regulação da temperatura, a retenção de material particulado, a reciclagem de poluentes e a conservação da biodiversidade, entre outros.

- Infiltração: Consiste na passagem da água da chuva através dos poros e microporos existentes na estrutura superficial e subsuperficial do solo. 


\section{RESULTADOS E DISCUSSÕES}

Através da quantificação das unidades de paisagem mapeadas, verificou-se que o bairro Nossa Senhora do Perpétuo Socorro é majoritariamente residencial unifamiliar. Do total de 1857 unidades identificadas (454.617 ha), apenas 17 foram classificadas como Prédios ( $1,07 \%$ do total de unidades de paisagem). Destes $41,17 \%$ possuem alto grau de impermeabilização (de 60 a 100\%) e 23,52\% possuem baixo grau de impermeabilização (de 0 a $30 \%$ ), sendo que $35,29 \%$ das Unidades possuem média impermeabilização (de 30 a $60 \%)$.

Já nas Unidades classificados como residências unifamiliares, que são a maioria, os números de baixa impermeabilização são reduzidos quase que pela metade, conforme mostra a tabela abaixo:

TABELA 1 - Comparação entre a impermeabilização do terreno causada por casas e prédios.

TABLE 1 - Comparison between soil waterproofing caused by houses and buildings.

\begin{tabular}{c|c|c|c}
\hline & $\begin{array}{c}\text { Grau de impermeabilização do } \\
\text { terreno }\end{array}$ & Quantidade & Área (ha) \\
\hline \multirow{4}{*}{ Casas } & $30 \%$ & 822 & 44,893 \\
& $60 \%$ & 300 & 12,9391 \\
& $100 \%$ & 461 & 17,620 \\
& $100 \%$ & 35 & 17,095 \\
\hline \multirow{4}{*}{ Prédios } & $30 \%$ & 822 & 44,893 \\
& $60 \%$ & 300 & 12,9391 \\
& $100 \%$ & 461 & 17,620 \\
& $100 \%$ & 35 & 17,095 \\
\hline
\end{tabular}

Esta característica do bairro de constituir-se por um grande número de residências unifamiliares (são 1840 casas - 85,89\% do total de biótopos-, ocupando uma área de 75.453 ha $-16,59 \%$ da área total) repercute na diminuição dos percentuais de impermeabilidade, pois, ao contrário dos prédios, essas casas geralmente possuem espaços livres com jardins, gramas e/ou outros tipos de estruturas permeáveis. Desta forma, o numero total de residências que possuem áreas livres é de 1572, o que representa $85,34 \%$ do número total de Unidades, ocupando 75,136 ha $(16,52 \%$ da área total). Esta informação pode ser 
visualizada na figura 3 que mostra o total de biótopos identificados no bairro, com toda a classificação feita através da chave de biótopos.

Verificou-se também que 968 biótopos (52.52\% do total de biótopos), que representam 359.581 ha $(79,1 \%$ do total da área de estudo) possuem baixo grau de impermeabilização (de 0 a 30\%). Já 563 biótopos (30.56\% do total de biótopos), que representam 39.717 ha $(8,73 \%$ da área total) possuem alto grau de impermeabilização e 311 biótopos (16.88\% do total de biótopos), que representam 14.503 há $(6,19 \%$ da área total) possuem médio grau de impermeabilização.

Comparando estes números com os encontrados por Lucas, Antunes e Figueiró (2008) no centro da cidade de Santa Maria - RS, onde a densificação urbana é mais acentuada, nos permite uma análise mais profunda sobre o processo de substituição de espaços livres por construções e por estruturas impermeáveis, em bairros que possuem maior número de prédios e estabelecimentos comerciais. Os autores verificaram que $34,25 \%$ dos prédios no bairro Centro não possuíam área livre, ou seja, estavam totalmente impermeabilizados e, mesmo dentre os que possuíam área livre, 50\% tinham alto grau de impermeabilização, totalizando $84,25 \%$ dos prédios, o que representa $12,1 \%$ da área total do bairro Centro. 


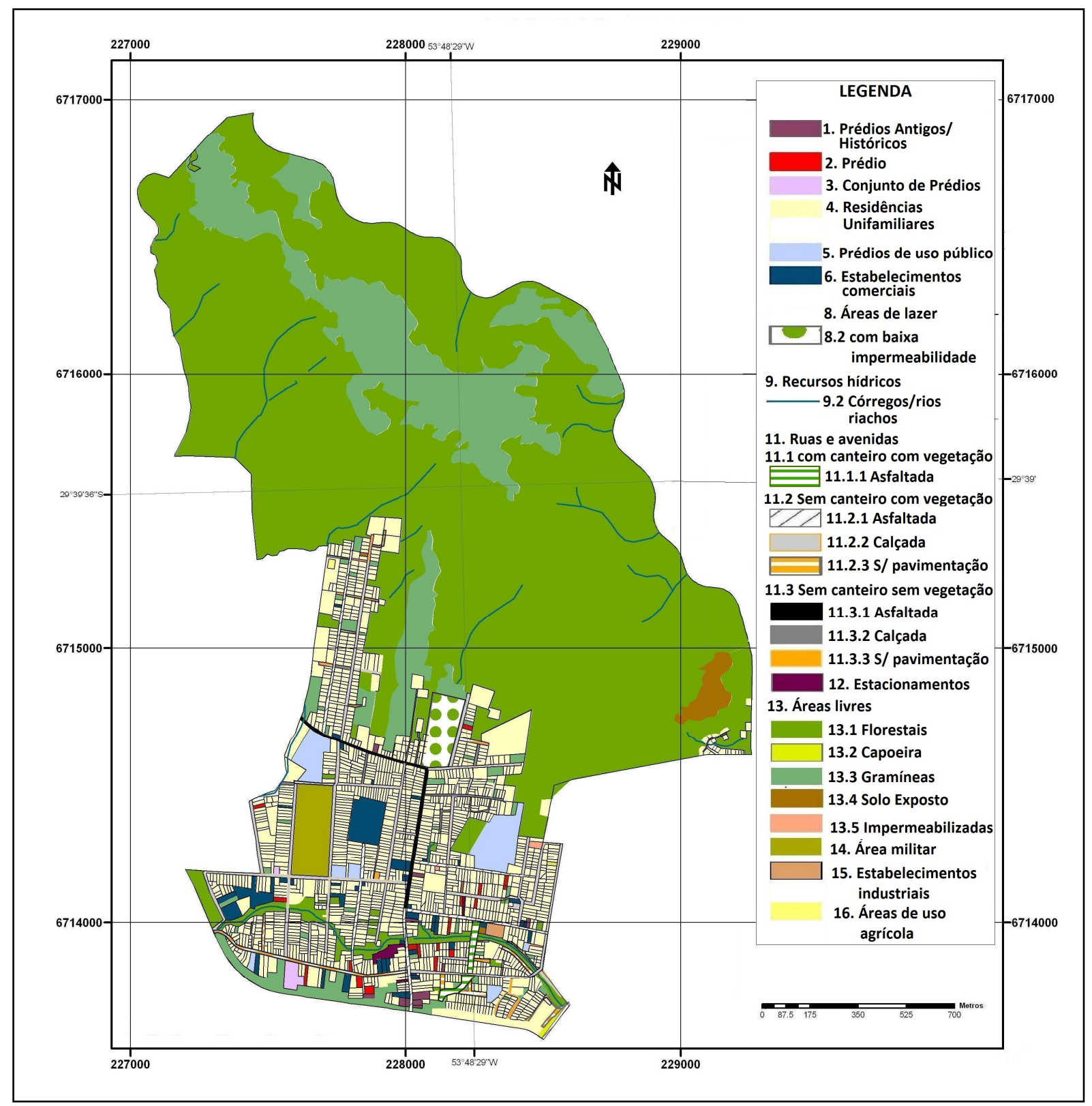

FIGURA 4 - Mapa dos biótopos identificados no bairro № Sa do Perpétuo Socorro.

FIGURE 4 - Map of identified biotopes in Nㅗ S $^{\underline{a}}$ do Perpétuo Socorro neighborhood.

Com relação ao verde urbano o bairro possui índices que podem ser considerados positivos: foram identificados 967 biótopos (52,07\% do total de biótopos) com presença de algum tipo de vegetação (árvore e/ou arbusto e/ou gramínea), sendo que a área ocupada por eles representa 372.553 ha, ou seja, $81,95 \%$ da área total. Já os biótopos que não possuem nenhum tipo de vegetação em suas áreas livres representam $14.34 \%$ do total dos biótopos. 
Considerando somente a presença de árvores foi identificado no bairro Perpétuo Socorro 1131 biótopos $(60,79 \%$ do total de biótopos), que representam $83,81 \%$ da área total e apenas 726 biótopos $(39,21 \%$ do total de biótopos) não tinham vegetação arbórea dentro de seus limites.

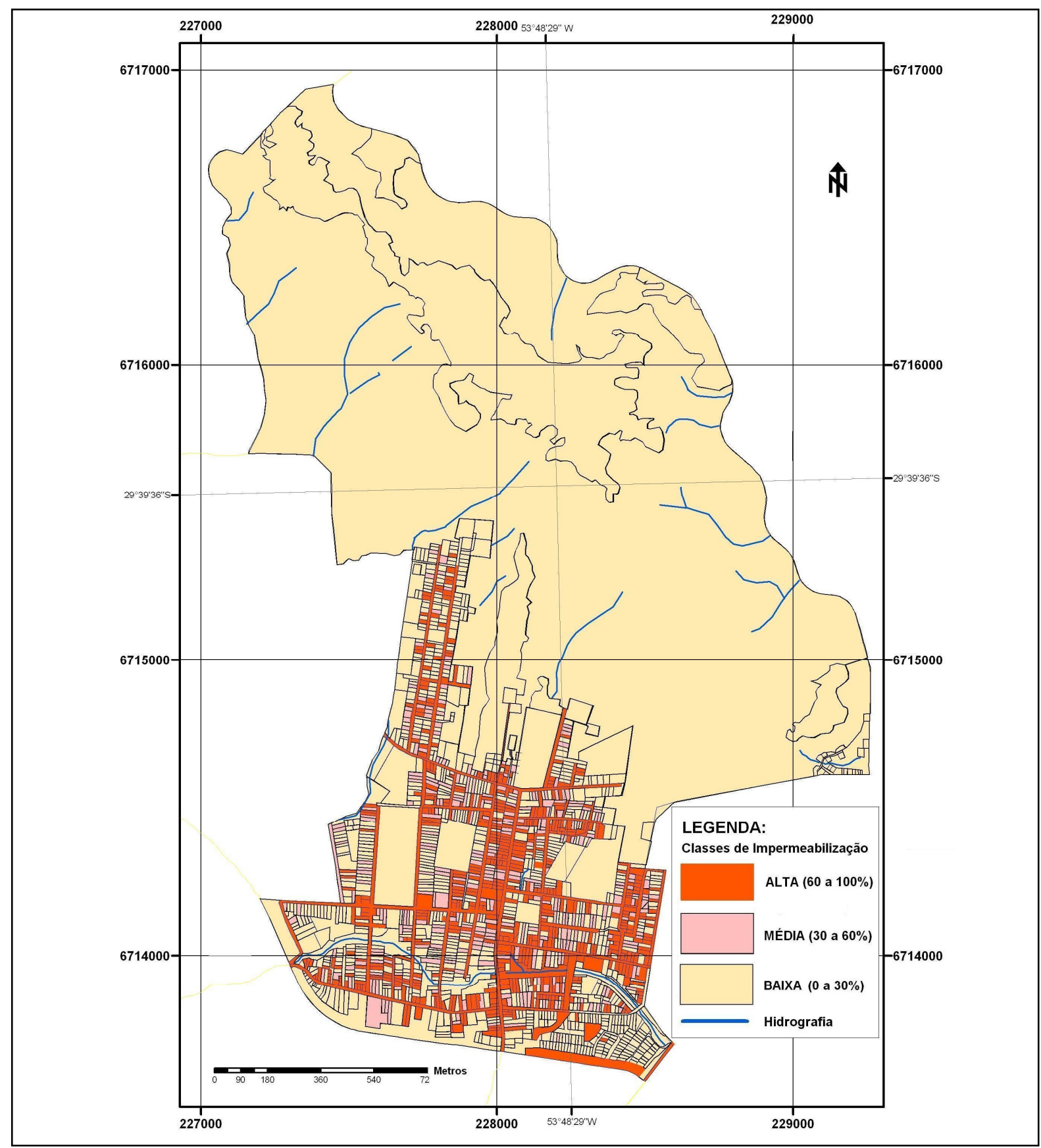

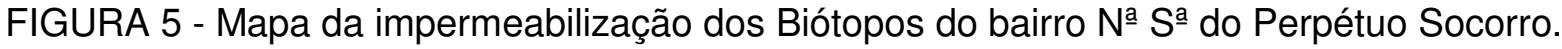

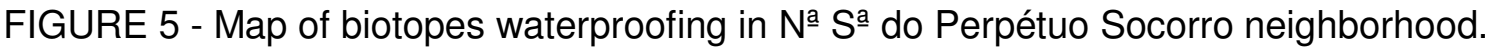

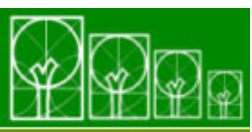


Estes números mostram que a relação de árvores por área ocupada é significativa, o que faz com que as funções ambientais desempenhadas pelas árvores sejam atingidas com mais facilidade.

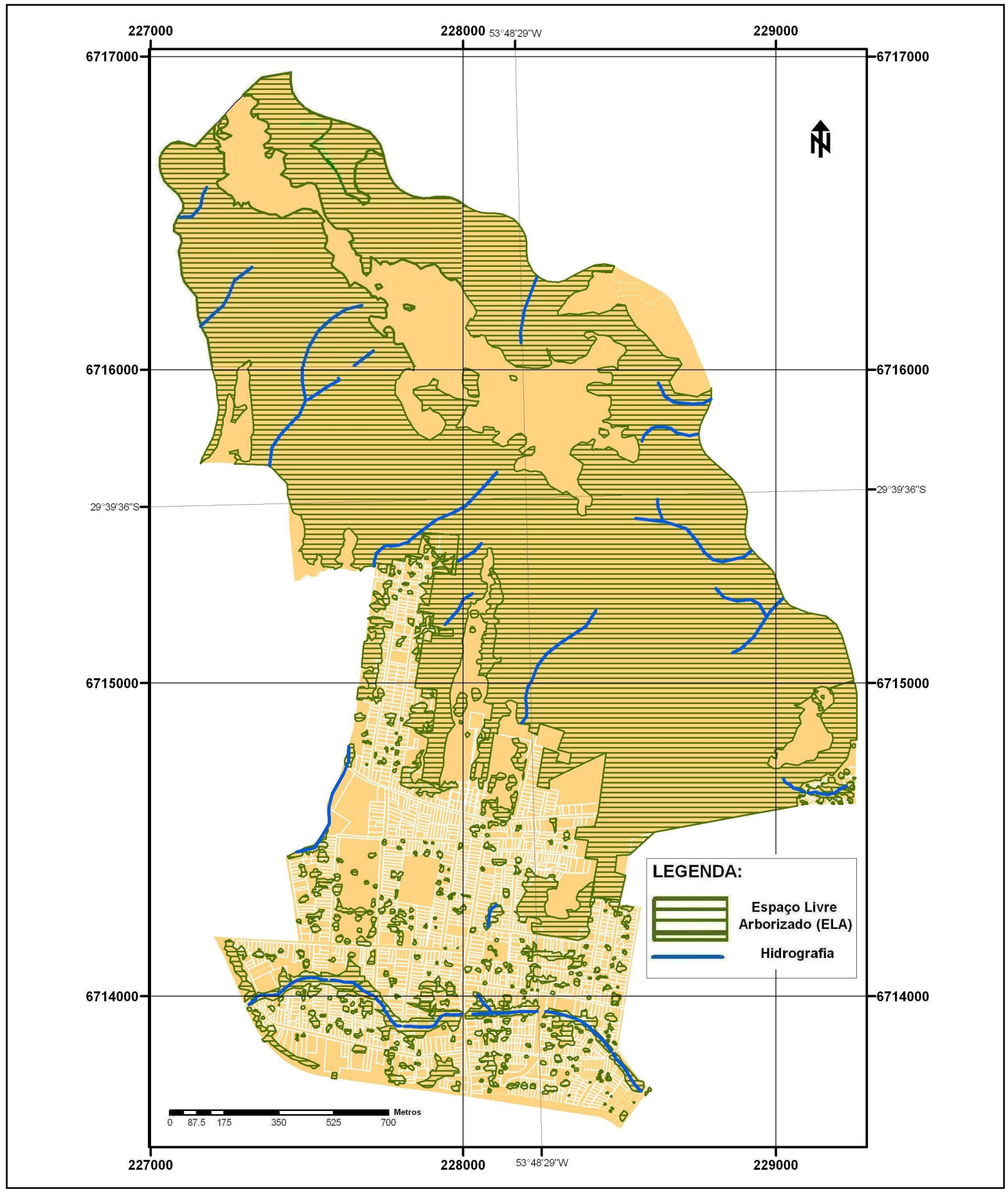

FIGURA 6 - Mapa dos Espaços Livres Arborizados do Bairro № S $^{\underline{a}}$ do Perpétuo Socorro.

FIGURE 6 - Map of Wooded Free Spaces in N ํㅗำ do Perpétuo Socorro neighborhood. 
Mais um dado importante que caracteriza a baixa impermeabilização do bairro Perpétuo Socorro se relaciona ao reduzido número de biótopos que não possuem áreas livres, apenas 17 biótopos ( $0,16 \%$ do total de biótopos), que estão nessa condição, sendo que somadas as suas áreas elas não ultrapassam os 0.735 ha, ou seja, representam $0,91 \%$ da área total. Já uma quantidade muito superior (1825 biótopos - 99,07\% do total de biótopos), possuem áreas livres, que somadas chegam a 413.036 ha.

Sob esta condição, convém lembrar que as áreas verdes são um tipo especial de espaços livres onde o elemento fundamental de composição é a vegetação. Para Buccheri Filho e Nucci (2006) estas áreas devem satisfazer três objetivos principais: ecológicoambiental, estético e de lazer. Ainda os autores citam que a vegetação e o solo permeável (sem laje) devem ocupar, pelo menos, $70 \%$ da área; proporcionando um uso e condições para recreação à população.

O bairro Nossa Senhora do Perpétuo Socorro se enquadraria positivamente nesta lógica, pois apenas 83 biótopos (19,34\% do total de biótopos) possuem algum tipo dessas estruturas (no caso desta pesquisa, calçada e calçamento), já o restante, 346 biótopos (80,65\% do total de biótopos) não apresentam calçadas e calçamento em suas áreas livres. Entretanto, 1492 biótopos, se considerarmos a presença somente de calçada, possuem, ainda que em pequenas parcelas, este tipo de estrutura impermeável em suas áreas livres.

Um dos fatos mais significativos encontrados no bairro Nossa Senhora do Perpétuo Socorrro refere-se ao número e as dimensões das áreas livres florestadas presentes. No total, foram identificadas 30 áreas livres florestadas, que ocupam uma área de 236,724 ha, mais da metade da área total do bairro (52,07\%). Estas áreas estão localizadas principalmente no limite com o rebordo do planalto, ao norte da área de estudo, onde as declividades são mais acentuadas e a ocupação por moradias fica um pouco mais difícil.

Estas áreas livres florestadas identificadas, além de contribuírem para que seja reduzida a impermeabilização do solo no bairro, possuem um significado importantíssimo para a funcionalidade ambiental, pois elas desempenham um papel importante no balanço hídrico, não ligado apenas ao aumento da água no solo, ou da precipitação, mas ao efeito regulador que elas exercem sobre esse balanço.

Outra importante contribuição para a funcionalidade ambiental é desempenhado pelas áreas livres com gramíneas, que ocupam uma área de 58,9 ha, que representam $12,95 \%$ da área do bairro, que somam ao total 45 biótopos. Outras áreas menores, mas que também contribuem para o alto índice de permeabilidade do bairro são as áreas livres com

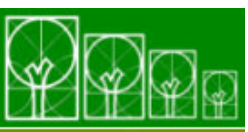

$\mathbf{S} \cdot \mathbf{B} \cdot \mathbf{A} \cdot \mathbf{U}$ Soc. Bras. de Arborização Urbana 
capoeira e com solo exposto; estas ocupam uma área de 322,561ha, o que representa $70,95 \%$ da área total do bairro.

De acordo com Spirn (1995), as árvores das ruas representam para a maioria das cidades seu maior investimento em vegetação. Elas influenciam o clima, a qualidade do ar e a aparência dos lugares onde as pessoas vivem e trabalham. Outro fato significativo é que a presença de ruas com calçamento de rochas e mesmo de estradas sem pavimentação asfáltica também influenciam para que a funcionalidade ambiental do bairro seja atingida com eficácia.

No caso específico de Santa Maria, o Plano Diretor de Desenvolvimento Urbano Ambiental (PDDUA) prevê, na Lei Complementar ํ‥ 034, no artigo 13ํㅜ, que trata das diretrizes do Sistema Viário Municipal, que se deve utilizar uma pavimentação alternativa que possibilite maior permeabilidade do solo, principalmente nas vias locais. E, ainda, promover a permeabilidade do solo nos canteiros centrais das vias urbanas e nos passeios públicos.

Nota-se neste sentido, que o bairro Perpétuo Socorro cumpre em parte esta especificação do PDDUA, pois, existem diversas ruas que não utilizam pavimentação asfáltica.

Outro dado interessante encontrado no bairro Nossa Senhora do Perpétuo Socorro foi a reduzida presença de estacionamentos, apenas 3; além disso, os mesmos estão classificados na faixa que vai de 0 a 30\% de impermeabilização, ou seja, com alto índice de retenção do escoamento superficial.

\section{CONCLUSÕES}

O diagnóstico das unidades de paisagem do bairro Nossa Senhora do Perpétuo Socorro, através do mapeamento e da caracterização dos biótopos, mostrou-se um instrumento valioso na análise das condições ambientais e da estrutura do espaço físico do bairro. Essa pesquisa com certeza servirá de base para um ordenamento mais adequado da ocupação e como apoio à preservação da biodiversidade e da qualidade ambiental existente. Além do mais, é um instrumento importante para a melhoria da qualidade ambiental da área, com a inserção de planos e diretrizes que visem ao alcance desta meta.

Os dados apresentados nesta pesquisa apontam o Perpétuo Socorro como um bairro (ainda que localizado na zona urbana) que possui atributos que evidenciam uma boa

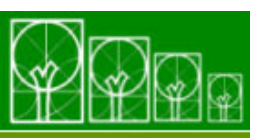

$\mathbf{S} \cdot \mathbf{B} \cdot \mathbf{A} \cdot \mathbf{U}$ Soc. Bras. de Arborização Urbana 
qualidade ambiental, quando em comparação com outros bairros da cidade. Os índices de cobertura vegetal encontrados são um exemplo disso, enquanto que grande parte dos bairros de outras regiões urbanas do Brasil, e até mesmo os localizados na mesma cidade, apresentam números que não ultrapassam o índice recomendado de 30\%, o Perpétuo Socorro tem $91,20 \%$ de vegetação arbóreo-arbustiva.

O que se pode constatar é que a obtenção destes níveis elevados de cobertura vegetal, sem dúvida alguma, se relacionam a existência das grandes áreas livres florestadas ao norte da área de estudo, que fazem parte da reserva da biosfera. Estas áreas possuem dimensões significativas, entretanto vem sofrendo lentamente a pressão da urbanização no seu entorno.

Os dados apresentados indicaram o total de 30 áreas livres florestadas, que representam em área um total de 236,7 ha, mais da metade da área total do bairro $(52,07 \%)$. Foram identificados também, 58,9 ha (12,95\% da área do bairro) de áreas livres com gramíneas.

Neste sentido, coloca-se como uma medida essencial para a manutenção da funcionalidade ambiental associada a essas áreas livres e/ou com vegetação, a criação de áreas protegidas, com a finalidade de reduzir a pressão imobiliária sobre esta que é o portal sul da Reserva da Biosfera da Mata Atlântica.

\section{AGRADECIMENTOS}

Á Universidade Federal de Santa Maria.

Á todos que contribuíram para a realização deste trabalho.

\section{REFERÊNCIAS BIBLIOGRÁFICAS}

BAKER, L. A. et al. Urbanization and Warning of Phoenix (Arizona, USA): Impacts, feedbacks and mitigation. Urban ecosystems, V.6.p.183-203, 2003.

BELÉM, João. História do Município de Santa Maria (1797-1933). Santa Maria: Editora UFSM, 1989.

BUCCHERI FILHO, A. T.; NUCCI, J. C. Espaços livres, áreas verdes e cobertura vegetal no bairro Alto da XV. Revista do Departamento de Geografia (USP), v. 18, p. 48-59, 2006.

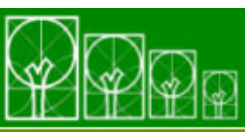

$\mathbf{S} \cdot \mathbf{B} \cdot \mathbf{A} \cdot \mathbf{U}$ Soc. Bras. de Arborização Urbana 
CARBONARI, M. P. Ecossistema insular: importância de seu estudo. Caderno de Ciências da Terra, 65. São Paulo: USP, 1981.

FIGUEIRÓ, A. S. Aplicação do zoneamento ambiental no estudo da paisagem: uma proposta metodológica. Dissertação de mestrado. Florianópolis: UFSC, 1997.

INSTITUTO BRASILEIRO DE GEOGRAFIA E ESTATÍSTICA. Censo Demográfico. Rio de Janeiro: IBGE, 2000.

LUCAS, C. A.; ANTUNES, R. L. S.; FIGUEIRÓ, A. S. Caracterização e Conflitos entre Vegetação Urbana e Qualidade ambiental no Bairro Centro da Cidade de Santa Maria/RS: Uma Primeira Aproximação. Geografia: Ensino \& Pesquisa, v.12, p.986-1007, 2008.

MELLO, A. C. de. A imagem de praças Tiradentes em Curitiba. Percepção em Geografia caderno 2, Departamento de Geografia da UFPR, Curitiba, p. 22-27, set., 1995.

MARCHIORI, J. N \& NOAL, V.A. Santa Maria: relatos de impressões de viagem. Santa Maria: Ed. da UFSM, 1997, 296p.

NUCCI. J. C. Qualidade ambiental e adensamento urbano: um estudo de ecologia e planejamento da paisagem aplicado ao distrito de Santa Cecília (MSP). 2. ed. Curitiba: O Autor, 2008. 150p.

RAMBO, B. A fisionomia do Rio Grande do Sul. São Leopoldo: UNISINOS, 1994.

ROCHA, J. R.; FIGUEIRÓ, A. S. Estudos de vegetação urbana e funcionalidades ambientais: uma breve revisão. In: IV Seminário Latinoamericano de Geografia Física, 2006, Maringá. Anais do IV SLAGF. Maringá: UEM, 2006.

SAITO, C.H. O estruturalismo na ecologia da paisagem. Revista Brasileira de Ecologia, $n^{\circ}$ 3, 1998.

SARTORI, M. G. B. Clima e Percepção Vol.2. 2000. Tese (Doutorado em Geografia) Departamento de Geografia/FFLCH/USP, São Paulo, 2000.

SILVA FILHO, D. S.; PIVETTA, K. F. L.; COUTO, H. T. Z.; POLIZEL, J. F. Indicadores de floresta urbana a partir de imagens aéreas multiespectrais de alta resolução. SCIENTIA FORESTALIS, n. 67, p.88-100, abr. 2005.

SIRKIS, A. Ecologia Urbana e Poder Local. Rio de Janeiro: ONDAZUL, 1999.

SPIRN, A. W. O Jardim de Granito - A Natureza no Desenho da Cidade. São Paulo. Edusp, 1995.

TROPPMAIR, H. Biótopos: importância e Caracterização. Geografia, Rio Claro, 14:57-67, 1984.

TURNER, M. G. Landscape ecology: the effect of pattern on process. Annual Review of Ecology and Systematics, 20:171-197, 1989. 